Conference

Circuit

\title{
ALADN 1996: Savoring stone soup
}

\author{
By Irene M. Hoffman
}

\section{The 1996 conference addresses major fundraising issues}

$\mathbf{T}$ he 1996 Annual ALADN conference was like savoring a serving of stone soup. ALADN is the recently formed Academic Library Advancement and Development Network, and "Stone Soup" is a fable that is a good metaphor for the outcome of the three-day meeting. ALADN met this year at the University of California at Irvine, March 5-9, to share ideas and strategies for library fundraising.

The fable "Stone Soup" is about three hungry soldiers who try to find nourishment in a village. The villagers are wary of strangers and hide their food. When the soldiers offer to make a soup from ordinary stones, the whole village becomes intrigued. One by one the villagers begin to share their precious ingredients to make a soup that will feed the entire village.

ALADN was like enjoying a full pot of stone soup. More than 80 library development professionals from the U.S. and Canada brought their ingredients to the mix that ended up nourishing the entire meeting. Joanne R. Euster (University of California, Irvine) opened the conference by stating that the meeting "is a testimonial to the importance that academic libraries place on fundraising."

\section{On sherpas and mountain climbers}

The keynote speaker was Victoria Steele (University of Southem California) who spoke on the library director/development director relationship, discussing the ideal relationship, common pitfalls, and strategies to improve the relationship. In her view, the ideal relationship is like that of the mountain climber and the sherpa: "Librarians are the mountain climbers, library de- velopment officers are the sherpas. Sherpas know the way up the mountain, the snow conditions, and crevices. In general, how to reach the goal by guiding the mountain climber to the top."

According to Steele, successful fundraising is the synergistic relationship between the development professional and the librarians. She talked about "triggering avalanches," identifying the common pitfalls of library fundraising that can interfere with reaching the goals. Keeping a clear vision, putting emphasis where it is needed, and setting priorities are areas where the library director and development officer need to maintain focus. Steele also shared her one simple skill to improve fundraising: use the word "consider" when formulating any kind of request to a potential donor. For example, "Would you consider a gift of. . ?" This makes it easier for the donor to think about the request before replying

\section{Partnerships and collaborations}

Lynn Trojahn (University of New Mexico, Albuquerque) gave a presentation titled "Look in Your Own Backyard!! Constituency Building for Libraries" in which she identified constituents by answering three questions: who uses the library? who needs to support the library? and who can use the credibility of the library? In identifying people and groups that answer these questions, Trojahn created a diverse and successful fundraising effort. Her presentation included overviews of her athletics partnerships and her work with corporations, alumni, faculty, and staff.

Amy Smith (California State UniversityFresno), Leslie DiBona (San Diego State University), and Irene Hoffman (California Polytechnic, San Luis Obispo) presented a model for a "Collaborative Approach to Library Development." Fifteen of the 22 California State 
University system libraries have development directors. Twice a year, these directors meet to discuss fundraising strategies. The group also communicates via e-mail to share information. discuss systemwide policies and procedures, coach and mentor each other, and collaborate on systemwide projects such as grants and surveys. One example was a job description survey that collected information on the variety of fundraising titles, duties, budgets, and staffing among the sister campuses.

\section{Development officers and gifts}

Another highlight was a presentation by Jim Asp (University of California-Irvine) who looked at the qualities of a great advancement officer and described a new paradigm to understanding the role of the development officer within higher education. The role of the development officer is a blending of salesperson, catalyst, manager, and leader, and by looking both externally and internally, these roles can be defined for each officer.

Johanna Christenson (University of California-Irvine) and Michelle Fletcher (University of North Carolina-Chapel Hill) gave a presentation called "Gifts in Kind: A Primer," which looked at how gifts in kind, regardless of type, are handled. To assess this process they recommend looking at the entry points for the gifts, what the library does with them, who accepts them on behalf of the library, who acknowledges the gifts, who accounts for the gifts, and who reports the gifts. By analyzing these areas, a clear, coordinated approach to accepting gifts in kind adhering to policies, IRS compliance, and reporting can be achieved. According to Fletcher, "a gift is a gift. Be sure to acknowledge and foster the culture of giving in the library."

\section{Annual funds and the Web}

The foundation of the giving program is the annual fund. According to Suzanne Sprinkle (University of California-Irvine) it is "the launching pad to boost people up to higher levels of giving." Its function is to bring in annual support, develop public awareness, identify potential major donors, provide opportunities to involve donors, and provide broad-based participation. Lynn Trojahn spoke on annual fund campaigns that bring in the bucks and build relationships. She identified the components that make these campaigns work: know what you are asking for, identify a key individual to chair the campaign, know what constituencies to ask, and put needs into a compelling context.

Selden Smith (University of Pennsylvania) presented on "Using the Web for Fund Raising and Recognition." Smith stated that "using the Web as a tool for library fundraising is just like any tool. It can be used well or not at all, just another tool in the toolbox." His primary principle is, "if you can imagine it, you can do it."

\section{Ethical persuasion and living endowments}

A rhetorician by training, Bob House (University of Arizona) spoke on the "Rhetoric of Fund Raising." House applied the art of ethical persuasion to the art of fundraising. Using the five P's of rhetoric - public, persuasive, purposeful, persona, and poetic - he gave tips on how to put together a strategy. He stressed that before making any moves on a donor, one should understand the rhetorical problem: the dynamic context linking the rhetor, the audience, history, competing actions, and timing. By mapping out strategies that answer these questions, the interaction between donor and development officer will be more successful. "The dialog between the two should be centered on where the donor's interests lie, not on the speaker," said House.

Samuel Huang's (Northern Illinois University) talk, "Fundraising: New Ventures for an Ordinary Academic Librarian," was far from ordinary. He detailed his success in targeting fundraising efforts to international students and how he expanded his friends group from 36 to more than 290 members in less than two years. His tips include relationship building and stewardship. Huang also spoke about the benefits of creating "living" endowments, so that for years to come the donor and his or her heirs may continue to help the endowment grow.

\section{Planning is under way}

There were many more speakers, activities, and advantages to this meeting than can be summarized within this article. ALADN continues to grow as an organization and to feed hungry library development professionals. Through its annual meeting and the listserv, ALADN is an ongoing "stone soup" for supportive and creative library development professionals. Planning for the 1997 annual meeting is under way. For information on ALADN or the LIBDEV listserv, please contact the author at: ihoffman@ library.calpoly.edu. 


\section{There's more than}

\section{ONE}

way to do most things. You can have

\section{ONE}

serials management company, and

\section{ONE}

document delivery service, and

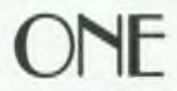

source for CD-ROM databases and yet another

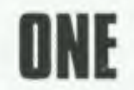

for full text, index and abstract database searching.

But why would you want more than

\section{ONE}

when there's

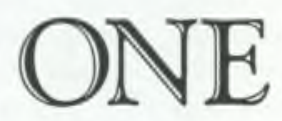

integrated source that can do it all for you?

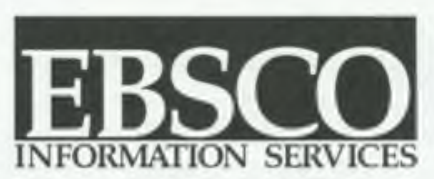

Phone: (205) 991-6600 - Fax: (205) 995-1636

Web site: http://www.ebsco.com

The Leader In Integrated Serial Information Management 